University of St. Thomas, Minnesota

UST Research Online

$9-2004$

\title{
Auction Fever: The Effect of Opponents and Quasi-Endowment on Product Valuations
}

James Heyman

University of St. Thomas, Minnesota, jeheyman@stthomas.edu

Yesim Orhun

University of Michigan - Ann Arbor, aorhun@umich.edu

Follow this and additional works at: https://ir.stthomas.edu/ocbmktgpub

Part of the Marketing Commons

This Article is brought to you for free and open access by the Marketing at UST Research Online. It has been accepted for inclusion in Marketing Faculty Publications by an authorized administrator of UST Research Online. For more information, please contact asle4660@stthomas.edu. 


\section{AUCTION FEVER:}

\section{THE EFFECT OF OPPONENTS}

\section{AND QUASI-ENDOWMENT ON PRODUCT VALUATIONS}

\section{JAMES E. HEYMAN, YESIM ORHUN, AND DAN ARIELY}

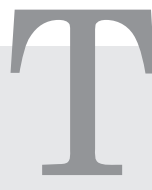

he wide adoption of dynamic second-price auctions as the format of choice for Internet-based (online) transactions has created an interest in understanding how individuals behave in such environments. The current work concentrates on two dynamic effects, which we call quasi-endowment and opponent effect, and finds that these effects may result in over-bidding. The results of two experimental auctions-one involving hypothetical bids and the other real-money bids-demonstrate that bids reflect valuations that include the nonnormative influences of the two factors. Quasi-endowment and opponent effects could lead to the behaviors of repeated bidding and sniping commonly observed in second-price online auctions such as eBay.

C 2004 Wiley Periodicals, Inc. and Direct Marketing Educational Foundation, Inc. JOURNAL OF INTERACTIVE MARKETING VOLUME 18 / NUMBER 4 / AUTUMN 2004 Published online in Wiley InterScience (www.interscience.wiley.com). DOI: 10.1002/dir.20020

JAMES E. HEYMAN AND YESIM ORHUN

are Ph.D. students at the Haas School

of Business, University of California at

Berkeley.

\section{DAN ARIELY}

is the Louis Alvarez Renta Professor of

Management Science at MIT's Sloan

School; e-mail: ariely@mit.edu

The authors thank Itamar Simonson,

Uri Simonsohn, Stacy Woods, Dina

Mayzlin, Ali Hortacsu, and Robert

Zeithammer for their stimulating

discussions concerning this project. 


\section{INTRODUCTION}

At 4 minutes to 7:00 on January 5, a 7-day eBay auction for an Olympus SLR IS-3 DLX camera ended. This was a typical auction with 10 different bidders, each placing between one and five bids. The person with the user name Belab submitted five proxy bids starting with one for $\$ 50.00$ on the second day of the auction and culminating with a final bid of $\$ 306.00$ placed 15 seconds before the end of the auction (a pattern of bidding called sniping). The example of Belab is interesting because it demonstrates the complexity and richness of behaviors in online auctions such as those hosted by eBay.

Belab's behavior is not an individual anomaly. In fact, multiple bidding and sniping are more the rule than the exception (Ariely \& Simonson, 2003; Bajari \& Hortacsu, 2003, 2004; Hossain, 2003; Ockenfels \& Roth, forthcoming; Rasmusen, 2003; Roth \& Ockenfels, 2002). The fact that this behavior is common raises the following questions: Why do so many bidders submit multiple proxy bids over the course of a single (second price) auction? Was Belab reacting rationally to new information gained from other bidders' actions? Was she over-weighting the information she received from other bidders in the auction compared with the extensive amount of information available commercially about this particular camera? Was she trying to conceal her true valuation in her early bids? Was she trying to fool some of the other bidders? Does this pattern of bidding have anything to do with the observation that more people join auctions toward their end? Was her understanding of her valuation for the camera changing during the auction? Was the prospect of not getting the camera once she had started bidding weighing heavily in her mind, and increasing her willingness to pay as seen in the cartoon (Exhibit 1)?

It has been argued by Ariely and Simonson (2003), among others, that for the average consumer, bidding in an auction is fundamentally different from buying a product for a fixed price either on- or off-line. Auctions are dynamic and competitive. Making decisions in such an environment could influence the process by which bidders come to understand their own valuation of the items in question and their willingness to pay for them. Moreover, auctions present their participants with the task of setting the maximum dollar amount they are willing to pay, which is very different from the more common decision of whether to buy or not to buy at a fixed and known price.

\section{EXHIBIT 1}

The Joy and Agony of Online Auctions: Competition and Attachment
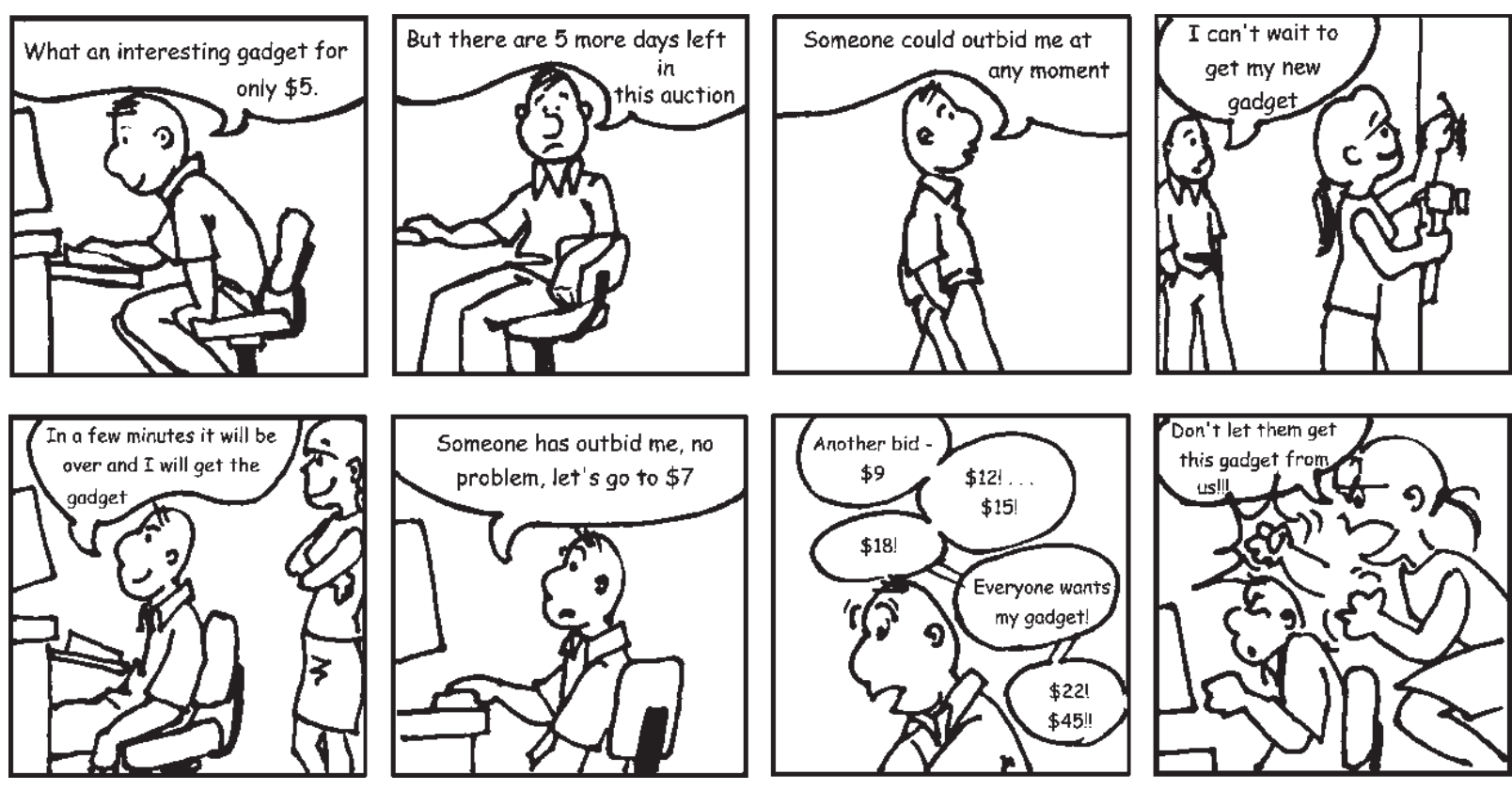
Evidence demonstrating the influences of these unique features of online auctions on the prices consumers are willing to pay has shown that final winning prices are positively related to the total number of bids and to the total number of bidders (Ariely \& Simonson, 2003). It has also been shown that bidders place too much value on information gathered within the particular auction in which they are participating, and are thus unduly influenced by that auction's reserve price (Häubl \& Popkowski-Leszczyc, 2001). Finally, it has been noted that bidders sometimes exhibit herd-like behavior in their pursuit of particular goods (Djolakia \& Soltysinski, 2001; Häubl \& Popkowski-Leszczyc, 2004). It seems that there is significant evidence suggesting that bidders' valuations for goods offered at auction change during the lifetime of the auction, leading to the repeated bidding and sniping behavior that is often observed in online auctions (Lucking-Reiley \& Reeves, 1999).

In the current work we propose two possible causes for an increased valuation for goods as the auction progresses: quasi-endowment and the "opponent effect." Quasi-endowment is a sense of ownership that bidders develop during an auction, even though they are not the owners in any common or reasonable sense of the word. Opponent effect, on the other hand, involves an increase in the subjective value of winning the auction when the behavior of the other bidders in the auction is perceived to be competitive. To investigate these two effects, we conducted an experiment to test people's intuitions of their responses to auction conditions, and conducted a set of real auctions where participants were able to bid with their own money for a variety of products. Both experiments demonstrated quasi-endowment and the "opponent effect." To the extent that the experiments resemble conditions similar to real auctions, these effects may have significant managerial implications for the optimal design of auction mechanisms.

The rest of this paper is organized as follows: We provide an overview of second-price auctions, since both of our experiments use variants of this structure; a detailed conceptualization of the two proposed effects follows, along with an overall description of the experiments; we then detail the experiments and results, and conclude with managerial implications and suggestions for future research.

\section{Second-Price Auctions}

Before delving deeper into the behavior of consumers in online auctions, it is useful to describe second-price auctions. The underlying logic of second-price auctioning is the key to the wide adoption of these procedures for online auctions, most notable in their implementation on eBay. Sometimes called Vickrey auctions, second-price auctions were first developed in 1893 to facilitate long-distance stamp auctions (Lucking-Reiley \& Reeves, 1999). The highest bidder in a second-price auction wins the auction but pays the amount of the second highest bid. ${ }^{1}$ Thus, the bid amount determines who will win the auction but not the amount to be paid. This structure compels bidders in second-price private-value goods ${ }^{2}$ auctions to bid their true valuations. Any deviation from this strategy puts them at risk for either paying more than their true valuation or losing the item to someone else at a price they were willing to pay.

The logic of this bidding strategy can be demonstrated by the following example. Consider the case of Alice, who is planning to participate in a second-price auction for a wristwatch. Suppose that she is familiar enough with the watch to know that she would be willing to pay up to $\$ 100$ for it (private-value good). How should Alice bid? If she bids more than $\$ 100$ and wins the auction, she might have to pay more than $\$ 100$, depending on the second-highest bid-creating an overall loss of utility. On the other hand, if Alice underbids and loses the auction, she might lose it at a price she was willing to pay-again creating an overall loss of utility. As Vickrey demonstrated, Alice's best strategy is to bid $\$ 100$, as this minimizes her chances of underbidding, while at the same time ensuring that she will not pay more for the watch than it is worth to her (Vickrey, 1961).

Another important advantage of second-price auctions, and one that is most important for online auctions, is

\footnotetext{
${ }^{1}$ In some second-price auctions, such as those on eBay, the winner actually pays slightly more than the second-highest bid. Although an increasingly common practice, this modification to second-price auctioning is of no theoretical or practical concern.

${ }^{2}$ In a private-value auction, the value of an item is known to each individual bidder and does not depend on other bidders. In a commonvalue auction, bids of different bidders contain information about the product's value. For this paper, we restrict our attention to privatevalue goods.
} 
that they can be used for asynchronous bidding over long periods of time. Asynchronous bidding is important because it lets bidders participate at any point during the auction. In particular, asynchronous bidding does not force bidders to watch and participate in the auction as it ends. This facilitates the presentation of product offerings for a substantial duration, thus allowing more people to observe and participate in the auctions while maintaining bidders' incentives to bid their maximum reservation prices.

Note that some online auction sites use variants of this auction structure. For example, eBay uses a dynamic second-price auction, called proxy bidding, where bidders can submit a bid for the maximum amount they are willing to pay at a point in time; the proxy bidding system displays the name of the bidder with highest proxy bid, but shows a price equal to the second-highest bid plus a small increment.

\section{Quasi-Endowment}

It is often said that possession is nine-tenths of the law. Is it also nine-tenths of the endowment effect? We believe that this question plays a vital role in understanding Belab's bidding behavior. Previous studies on the endowment effect have focused on how people's valuation for an item changes based on whether they currently own the item (Kahneman, Knetsch, \& Thaler, 1990; Thaler, 1980). In general, experiments on the endowment effect have shown that the average selling prices are typically more than twice as high as the average buying prices (Kahneman et al., 1990; Thaler, 1980), and the gap between selling and buying prices is typically described as a manifestation of loss aversion (Bar-Hillel \& Neter, 1996; Carmon \& Ariely, 2000). According to the basic idea of loss aversionthat losses have greater hedonic impact than gains (Kahneman \& Tversky, 1979; Tversky \& Kahneman, 1991)-letting go of an item is more painful than not obtaining this same item. Thus, when an item is a part of one's endowment, giving it up is viewed as a loss, whereas passing up the opportunity to obtain the same item is perceived as a forgone gain. The gap between selling and buying prices presumably reflects this difference in pain (Carmon \& Ariely, 2000).

Attributing the endowment effect to loss aversion implicitly assumes that individuals develop some attachment to the items they own or get. Thus, one possible mechanism for the endowment effect is that ownership can cause increased attachment to items, which increases their subjective value for the owner (Beggan, 1992; Beggan \& Scott, 1997). Indeed, Strahilevitz and Loewenstein (1998) directly examined the role of attachment in the endowment effect, finding significant effects of increased attachment due to ownership, causing an increase in subjective valuation, which in turn could ultimately lead to the observed endowment effect (see also Pierce and Kostova, 2002).

The volumes of research on the endowment effect have all been based on cases where the seller has unambiguous physical or legal possession of the item in question. In connecting ownership and its effects on valuations with online bidding behavior, it is possible that even without a legal claim on an item, high bidders could develop a feeling of ownership during the period of time when they are the highest bidders, leading to changes in valuation similar to those brought about by true ownership. We call this attachment to an un-owned item the "quasi-endowment" effect: "endowment" because the buyer can construct a reference point such that losing the auction will be coded as though they had actually lost the item; "quasi" because we believe this counterfactual perception is only a weakened or partial perception of ownership.

One possible psychological perspective on partial ownership is based on the concept of graded membership that has been articulated by Rosch $(1973,1975)$. One example of graded membership involves a robin and a penguin: a robin and a penguin are not either birds or not birds, but instead have a membership relation to the bird category such that membership is stronger for the robin when compared with the penguin. Applying this model of graded membership to the concept of ownership suggests that perceived ownership transcends the dichotomous view of physical or legal ownership of property, and includes shades of partial ownership in cases where ownership is not clear (for example, in online auctions). To test whether the theory of graded membership can be applied in general to the domain of ownership, we conducted a study with 35 participants. In the study, we asked participants to indicate their perceived level of ownership for different cases along a seven-point 
scale, anchored with "very low sense of ownership" on the left and "very high sense of ownership" on the right. We were interested in finding out whether participants could differentiate ownership along this dimension and whether there would be agreement across individuals with regards to the ownership level. The questions covered cases that spanned a large range of ownership, including borrowing a friend's bicycle for a period of time, bidding on a bike on eBay, having a bike on layaway, having one's bike stolen, lending a bike to a friend, having a gift certificate toward a bike, and so forth. The results showed that the adoption of the graded-category concept of ownership is appropriate, as individuals reported different feelings of ownership along the scale (average of responses across individuals ranging from 1.8 to 6.8), and, more importantly, all participants were relatively consistent in their evaluations along this scale (as shown by relatively small standard deviations ranging from 0.7 to 2.1 , with a mean of 1.5 ).

Relating the idea of graded ownership to the endowment effect, we would expect that people who own an item will show a high level of ownership and thus a high level of endowment, while individuals with a lower but nonzero sense of ownership should show a correspondingly lower but still observable endowment effect. In terms of graded ownership and online auctions, we hypothesize that the greater the amount of time that bidders are involved with an auction, the more their sense of ownership will increase. We also hypothesize that this effect will be exacerbated by the amount of time that a bidder is actually in the lead, so that bidders who think they are the highest bidders in the auction will increase their valuations. Due to the asymmetric disutility associated with losses (Kahneman \& Tversky, 1979) higher levels of endowment are expected to result in higher bids.

A final aspect of online auctions that may strengthen the effects of quasi-ownership is the fact that a number of people simultaneously participate in online auctions but typically do not monitor the auction continuously or even frequently. (For example, a typical bidder may check a 7-day auction for a DVD only once or twice.) As a consequence, online auctions can create a situation where multiple bidders share the sense of partial ownership that is due to being the highest bidder, even though only one of the bidders is the lead bidder at any one time. In such cases, even relatively weak effects of quasi-ownership for each individual can aggregate to create much larger effects for the auction as a whole.

\section{Opponent Effect}

Auctions are by their nature situations where bidders are placed in opposition to other bidders, where the outcome-in terms of who gets the item and how much they pay for it-is jointly determined by the behavior of multiple bidders. This kind of pricing situation is clearly very different from the regular retail shopping experience where (aside from a few gifts during the holiday season or special sales) there is little or no sensitivity to other shoppers.

We should note that there is another form of sensitivity to others that is common to both auctions and fixed-price purchasing: sensitivity to the information others are providing (information about the value of the product, the reputation of the seller, and so forth). Cases where the actions of others carry useful information are considered common value, where the information about the value of the transaction resides, at least in part, outside of the individual bidder.

The interesting question is whether the influence of others extends also to private-value auctions where the information component plays no role. We limit our discussion and the experiments to these private-value cases (in which the value of the item is known and where the small amount of information in the auction should have no effect on the knowledge one has about the item in question).

There are two main sources of evidence for how other people's actions can influence an individual's bidding behavior: the way auctions are discussed, and some strategic behavior during auctions. In terms of how auctions are discussed, it is very common for bidders to refer to the outcome of an auction as "winning" and "losing," and not, for example, as buying. Many people acknowledge that the competitive element adds excitement to bidding in online auctions and in particular to the joy of winning. The reference to "winning" and "losing" auctions suggests that this is a salient component, and perhaps that bidders get caught up in the momentum or otherwise derive some utility from this aspect of the auction. There are 
several psychological theories that support this possibility, including self-perception (Bem, 1965), goal achievement (Kaplan \& Middleton, 2002), decision under hot states (Loewenstein, 1996), and reasonbased choice (Shafir \& Simonson, 2000). A second type of evidence demonstrating the competitiveness and sensitivity of bidders to others comes from examination of sniping behavior (bidding in the last few seconds of the auction, not giving other bidders an opportunity to react to the bid). Sniping occurs despite the incentives to bid only once, not to watch the online auction in real time, and not to submit bids very late in the process (Ockenfels \& Roth, forthcoming; Roth \& Ockenfels, 2002). One explanation for sniping is that bidders might hold off bidding to the last moment in order to strategically hold back information until the last minute of the auction, to avoid price wars triggered by competition (Bajari \& Hortacsu, 2003; Häubl \& Popkowski-Leszczyc, 2004). This explanation for sniping emphasizes the sensitivity of online bidders to other bidders, as well as the competitive nature of online auctions.

To summarize, we presented two mechanisms that can dynamically influence the valuations of items and the bids placed as the auction unfolds: quasi-endowment and the opponent effect. The following two experiments are designed to test whether these two mechanisms take place in auctions. To the extent that the results support these two mechanisms, this would also increase our confidence that these two mechanisms underlie the commonly observed behavior where bidders submit multiple bids in a single auction.

\section{EXPERIMENT 1: BIDDING SURVEY}

The purpose of this experiment was to test for the quasi-endowment and opponent effects. We chose a survey-based experimental method because it is more logistically tractable than laboratory experiments, and because it allows us to gather respondents' intuition about the questions at hand.

Subjects. A total of 92 students at the University of California at Berkeley participated in this survey. Respondents were approached around campus and asked to participate in a short survey.
Design. There were four different questionnaire forms based on a 2 (high competition vs. low competition) $\times 2$ (low duration of ownership vs. high duration of ownership) design. Each condition presented a basic common scenario, followed by manipulations. The basic scenario was:

Suppose that you are shopping for a particular new watch with a retail cost of $\$ 75$ that you want badly. You learn that a local store is offering the watch in an auction. In this auction, the store management asks each potential buyer to write down in an envelope the highest price he or she is willing to pay for the watch. There is no limit on the number of bids anyone can submit and all of the envelopes are placed into a large glass bowl on the counter. The auction starts on Monday morning and on Friday evening all the envelopes will be opened and the watch will go to the highest bidder, but the highest bidder will pay the price set by the second highest bidder plus $10 \varnothing$. At the end of every day, the name of the highest bidder will be posted on the glass bowl. However, the auction goes on without interruption, and the envelopes of the top two bids always remain in the bowl.

The competition manipulation altered the number of bids that were in the glass bowl on Friday. In the lowcompetition condition, subjects were told that there were only "a few bids in the bowl." In the high-competition condition, they were told that there were "a lot of bids in the bowl." The opponent effect was estimated by the difference between final bids when there were a few envelopes in the bowl and a lot of envelopes in the bowl.

The duration of ownership was manipulated by describing a scenario where the participant's first bid was on Monday (long duration or ownership) or today-Friday (low duration of ownership). In the long duration of ownership condition, subjects were asked to imagine that they had submitted a bid on Monday and were told that as of Monday evening they were listed as the leading bidder, but that when they passed by the store the next time on Thursday evening they were no longer the highest bidder. ${ }^{3}$ In

\footnotetext{
${ }^{3}$ Note that this operationalization of ownership duration is only one of many ways to empirically test the effects of partial ownership.
} 
the short duration of ownership condition, subjects were asked to imagine that they knew about the auction since Monday but did not have a chance to pass by the store until Friday. The quasi-endowment was estimated by the difference between final bids on Friday varied based on their personal bidding history during the week (contrasting the long and the short duration of ownership conditions). In summary, these two treatments differed in that one group-the long duration of ownership condition-bid on Monday, temporarily held the lead and then could bid again on Friday. In contrast, the second group-the short duration of ownership condition-could only bid on Friday.

After reading the complete scenario including the manipulations, participants were asked to imagine that this was the last day of the auction (Friday), their last chance to place a bid for this watch, and were asked to circle the bid they would place today from a list of possible bids ranging from 1 to 100 .

Results. Initial statistical analysis consisted of an Analysis of Variance (ANOVA) using the stated bid as the dependent variable against the independent variables of competition level and duration of ownership condition. The overall model was statistically significant $[F(3,87)=3.20, p=.03]$ and the overall results (Figure 1) supported both the quasi-endowment and the opponent effect hypotheses. Follow-up analysis of the quasi-endowment manipulation demonstrated that having a leading bid on Monday caused subjects to submit higher final bids on Friday. Subjects who were told they were in the lead after placing their Monday bids offered $\$ 72.77$ whereas subjects who missed the opportunity to participate early on in the auction offered an average of $\$ 68.31$ as their Friday bid $[F(1,87)=3.23, p=.035]$. Follow-up analysis of the opponent effect demonstrated that auctions with higher competition cause bidders to increase their bids. On average, subjects in the high-competition conditions bid an additional $\$ 5.66$ on Friday $[F(1,87)=$ $5.40, p=.011]$. Perhaps more striking is the fact that the average bid in the low competition (\$67.64) would only fall in the 20 th percentile of the high-competition bids.

Given the opponent and quasi-endowment main effects, it is perhaps natural to wonder whether these

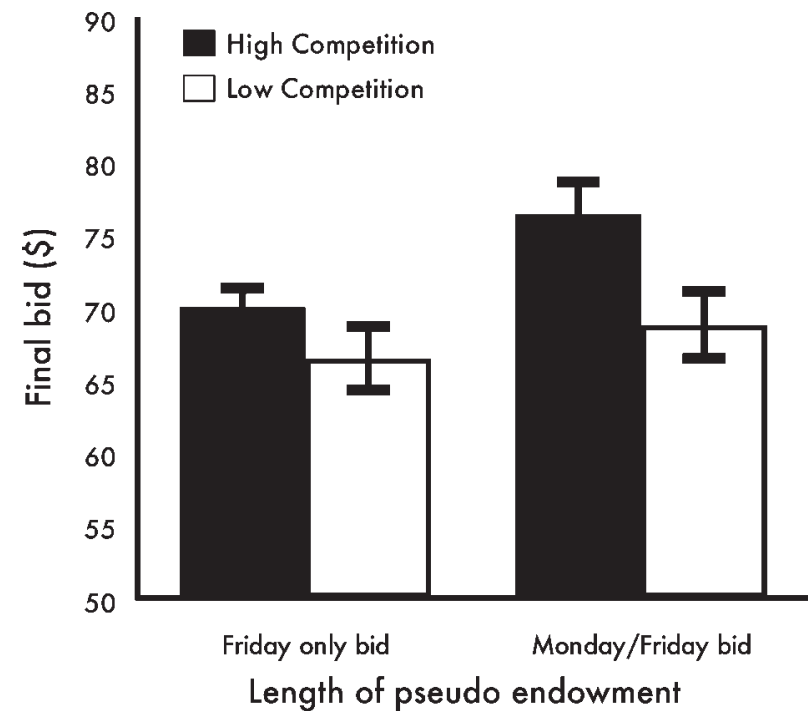

\section{FIGURE 1}

Bid Magnitude in Experiment 1 as a Function of Competition and Quasi-Endowment. Error Bars are Based on Standard Errors

two factors will have an ordinal interaction between them such that knowing that one was in the lead on Monday and facing heightened competition on Friday would result in even higher bids. Although a visual inspection of the results in Figure 1 seems to support such an interaction between quasi-endowment and opponent effects, the analysis does not support this interpretation and shows an insignificant interaction term $[F(1,87)=.726, p=.397]$. Clearly, these results should be interpreted with caution, but they do suggest that the two factors are additive.

Discussion. Experiment 1 was designed to test two possible reasons for multiple bidding in online auctions: quasi-endowment and opponent effect. The results suggest that both of these factors are likely to be implicated in the dynamic changes to valuations that online bidders experience as auctions unfold. In particular, as auctions progress, individuals who are the highest bidders for longer durations feel more attached to the item in question and hence are willing to submit higher prices. Similarly, bidders who face higher competition increase their final bids.

One of the obvious shortcomings of Experiment 1 is that it used a pencil and paper survey depicting a 
hypothetical situation, asking subjects for an appraisal of their behavior under those conditions, but did not measure actual behaviors. Due to this limitation, the results hold only to the extent that subjects' intuitions of their own behavior match real behavior in these situations. A second possible shortcoming could result from a misunderstanding of second-price procedure. The instructions of the experiment clearly explained the logic and mechanism of second-price auctions, but given the fact that the behavior was only hypothetical and included no incentives to read the instructions carefully or follow them, it is possible that subjects did not follow the logic of the second-price procedure.

Experiment 2 was designed to provide a conceptual replication of Experiment 1, eliminating the possible difficulties with this experiment. For this purpose, Experiment 2 used real auctions where subjects bid their own money on different goods, received more detailed instructions about second-price auctions, and finally repeatedly experienced second-price auctions and learned first hand about this procedure.

\section{EXPERIMENT 2: REAL-MONEY AUCTIONS}

Experiment 1 supported both of our hypotheses but potentially suffered from limitations discussed above. To address these limitations, we conducted realmoney auctions in a laboratory experiment that included treatment conditions analogous to those of the first experiment, and repeated this process for four within-subject replications. Finally, since the question of private vs. common value is central to the normative theory of how bidders should behave in reaction to the bids of others, two of the auctions in Experiment 2 were for gift certificates with a known face value. We argue that if any product (aside from money) can be considered as private-value goods, it is this type of good.

Subjects. Subjects were 140 students (70 male, 70 female) who, in return for participating, received partial class credit in an undergraduate marketing class. At the time of these experiments, auctions and associated behaviors had not yet been covered in class. To control for any social obligation effect, the subjects were instructed that receiving course credit was contingent on attending the lab and that bidding on any of the products was strictly optional.

Design. The design was 2 (duration of ownership) $\times 2$ (competitiveness) $\times 2$ (one of two opposite order of auctioned goods) $\times 4$ items to be auctioned. The first three factors were between subject manipulations, and the last one was within subject replication. As part of the instructions, subjects were told that they were being divided up into six-person auction groups across the classroom computer network. In fact, they were bidding against five computerized scripted competitors that varied according to the experimental conditions (see also Häubl \& Popkowski-Leszczyc, 2004 , for similar procedures). Subjects were asked to enter a code name of a certain type. The computerized bidders used the same type of code in order to create the impression for subjects that they were bidding against other people in the room. The auctions themselves were in discrete rather than continuous time (see Ariely, Ockenfels, \& Roth, 2004), with nine periods of bidding. On each of the rounds, after submitting their bid (staying with their previous bid or raising it) and a short random time interval, the auction progressed to the next round (or to the end of the auction, if this was the last round). This approach was used in order to control the number of bids subjects were able to place and to eliminate any effects that could be imposed by time pressure toward the end of the auction.

The competitiveness condition was defined by the total number of bids generated by the five computerized bidders in the first seven rounds. In the low-competition condition there were three to five bids in addition to the subject's bid, whereas in the high-competition condition there were between 20 and 35 bids (including multiple bids by the same computerized bidders).

Comparable to the duration of ownership manipulation in Experiment 1, the exposure length factor was defined by the number of bidding rounds that subjects participated in and thus the number of times they could perceive themselves to be at the lead. The analogy for this manipulation is an auction in which a bidder can observe and participate once each day across 9 days. In the long exposure condition, subjects participated in all nine of the bidding rounds, increasing their bids as they pleased and spending at least a part of the rounds at the lead. A log on the 
side of the screen indicated the cumulative bidding history throughout the auction. In the short duration of ownership condition, subjects were not allowed to participate until the eighth round. During the rounds that they were not allowed to actively participate, subjects were informed about the current round number (much like the knowledge of the day of the week) and the overall duration of the auction remained constant across all conditions. Once subjects reached the eighth round, all subjects were presented with the same log on the side of the screen, showing all bidding histories. This information included all bid data up to that point, including bid amounts and round numbers for each bid. Much like eBay's proxy bidding system, the amounts revealed were the second prices at each point. Providing this information to all subjects was done to keep the information of the bidding history the same across conditions and to vary only the participation itself. After observing the complete bid histories, subjects in all conditions were given the opportunity to bid on the final ninth round.

After an auction ended, the winners and all bids histories were revealed and the next auction started. This procedure continued until all four auctions were completed. The products used in the auctions were a University of California at Berkeley T-shirt, a half pound box of Godiva chocolates, a $\$ 15$ gift certificate for a local music store, and a $\$ 15$ gift certificate for Amazon.com.

Procedure. Participants were instructed to arrive promptly at the assigned time and, due to the extensive instructional period, latecomers were not seated. Participants were allowed to sit at any of the available computers, consistent with the cover story that they were bidding electronically against randomly formed groups of other bidders.

Once everyone was seated, 15-20 minutes of instructions were given regarding the bidding procedure, paying particular attention to the logic of secondprice auctions. ${ }^{4}$ Next, subjects were instructed about

\footnotetext{
${ }^{4}$ It is interesting to note that while Vickrey received the Nobel Prize in Economics for showing that second-price auctions are incentive compatible (which implies that this is a nontrivial insight), many treatments of online auction behavior assume that bidders intuitively understand the strategic implications of this structure.
}

probabilistic trials where at the end of the four auctions one of the auctions would be selected at random and only the outcome of this auction would be honored. This procedure was used to accommodate budget constraints and to prevent changes to reservation prices across auctions, thus allowing us to treat the four auctions as independent. Subjects also received specific instructions and examples on how to use the bidding software. Once there were no more questions, subjects were instructed to click the Start button, enter their screen name, and start bidding.

As noted earlier, each subject had the opportunity to bid in four separate auctions for the following items: a University of California at Berkeley T-shirt, a $\$ 15$ gift certificate for Amazon.com, a $\$ 15$ gift certificate for a local music store, and a half-pound box of Godiva chocolates. Based on pretesting and previous experiments, we anticipated that participants' valuations of the items would be between $\$ 5$ and $\$ 10$. The different items were selected to represent a wide variety of product types. The gift certificates were selected because their value is perfectly defined, the chocolates because of their high hedonic nature, and the T-shirt because the university store's standard retail price for the T-shirt was reasonably well known to the students.

Each individual auction began with the name of the auctioned item. The retail prices of the T-shirt and chocolates were not listed. In every round in which the subjects could participate (excluding the blocked rounds for subjects in the short duration of ownership condition), they were shown a list of everyone that had changed their bid in the previous round, the screen name of the individual bidder, the current highest bidder, and the highest bid (based on the second-highest bidder). Subjects were given the option to either increase their previous bid or keep their previous bid (which could have been 0). A counter identified the current round and subjects were separately alerted when the penultimate and final rounds occurred. After the final round, the screen showed the auction's winner and the final price paid (based on the second price). The program then proceeded to the next item and the above process was repeated. Once all items had been auctioned, the program notified each user as to which of the auctions was selected to be the one that would be honored, and 
the outcome of that auction. If the subject had the highest bid in the selected auction, they paid for the good with their own money and took the item. If the subject did not have the highest bid in the selected auction, they did not pay anything and did not get any item.

Results and Discussion. Of the 140 subjects, there were 10 that failed to place a single bid. Because these 10 were spread across the experimental conditions, we concluded that, for whatever reason, they simply chose not to participate or did not understand the instructions. Most likely, these subjects did not want any one of the items offered for auction, which is a common problem in small experimental auctions. ${ }^{5}$ All of the statistical analysis that follows is based on the remaining 130 subjects, who bid at least once on at least one item.

The products were offered sequentially in one of two orders. One group ( $n=66$ ) bid on the products in the following order: Amazon.com gift certificate, Rasputin (a local music store) gift certificate, university T-shirt, and the box of Godiva ${ }^{\circledR}$ chocolates. The second group $(n=64)$ was offered the identical products, but in the opposite order. The average bids across all products for these two groups, $\$ 5.96$ and $\$ 5.65$ respectively, were statistically indistinguishable $[t(128)=.666$, $p=.506]$. Pairwise analysis of each product within their respective order conditions shows a similar pattern. Moreover, bids did not change systematically as the subjects gained experience with the auction. The stability of performance across the four auctions suggests that the probabilistic aspect of the auctions (where only one out of the four would be carried out for real) indeed helped to eliminate budget constraints, and that the instructions were sufficiently clear to ensure that the behavior in the first auction was similar to that in later auctions. Finally, there were no significant differences across four products, which also suggests that all products had similar private-value components. Based on this analysis we eliminated product type and order effect from the analysis and treated the four auctions for each subject as independent replications. The rest of the analyses

5 This is the reason that most of the laboratory work on auctions has used money as the item offered. Money is not only the perfect private-value good, but it is also a good that all participants desire.

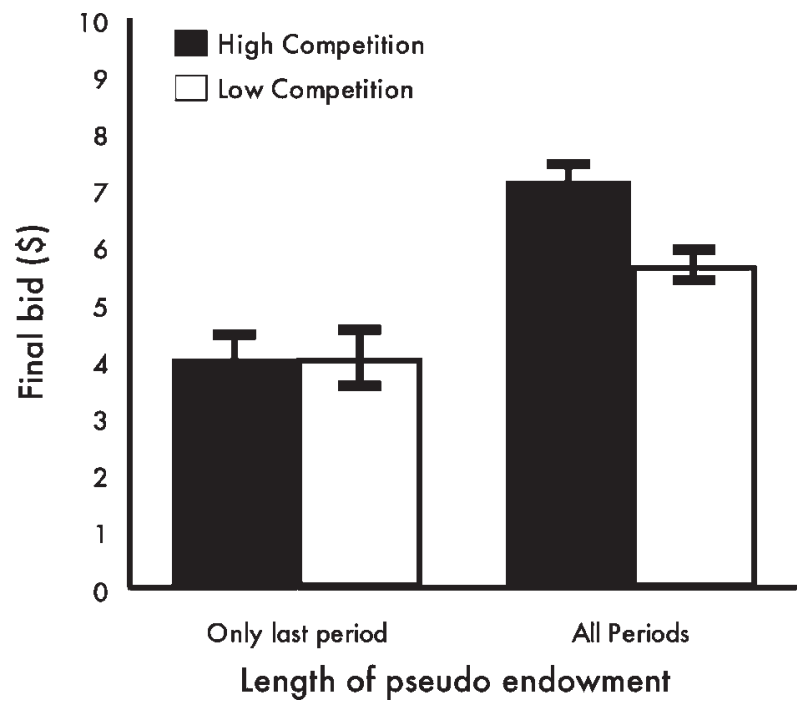

\section{FIGURE 2}

Bid Magnitude in Experiment 2 as a Function of Competition and Quasi-Endowment. Error Bars are Based on Standard Errors

are based on a 2 (duration of ownership) $\times 2$ (competition) $\times 4$ (replications) mixed subject design.

The statistical analysis was conducted using an Analysis of Covariance (ANCOVA) with the dependent variable (average bid) being compared across the treatment conditions of exposure and competition while controlling for the only demographic information that was available to us-gender. ${ }^{6}$ As can be seen in Figure 2, the overall results replicated those of Experiment 1, and the overall F-statistic was significant: $[F(4,125)=5.88, p<.001]$. The average bid for the subjects in the long duration of ownership condition was $\$ 6.39$ as opposed to $\$ 4.02$ for those people who came in just prior to the last round (short duration of ownership). This difference of $\$ 2.37$ is highly significant substantively as well as statistically $[F(1,125)=12.79, p<.001]$. We take this as evidence of the quasi-endowment effect: The very experience of

\footnotetext{
${ }^{6}$ The results are robust under inclusion or exclusion of the gender effect. Although the gender difference was only weakly significant $[F(1,125)=2.94, p=.089]$ the additional $\$ 0.73$ in men's average bids is a potentially substantive difference given the range of observed bids. This difference could be due to the specific products that we selected, to a more favorable outlook on auctions, or to other differences such as sensitivity to the endowment effect (Strahilevitz \& Loewenstein, 1998).
} 
bidding on a product increases valuations of that product. Similar to Experiment 1, these results also support the opponent effect $[F(1,125)=3.10, p=$ .045]. Although both the opponent and quasi-endowment effects found in Experiment 2 replicate those of Experiment 1, they do so in a more realistic environment, with auction rules that are more clearly explained, and where subjects bid with their own money for products. Experiment 2 also provides a more specific definition of competition. While in Experiment 1 an increased number of prices could have been due either to a large number of bidders or to multiple bids, in Experiment 2 the number of bidders remained constant (the subject plus five scripted bidders), and the manipulation of competition was limited to the number of bids submitted by this fixed pool of bidders.

Another difference between the lab and survey experiments is that Experiment 2 provides marginal support to an ordinal interaction effect $(p=.06)$, where the quasi-endowment effect is stronger under conditions of high competition. The simplest explanation is that the quasi-endowment operated more strongly when competition was fierce. A different interpretation is that being limited to observing the bidding information prior to the last round eliminated much of the motivation to participate in the auction altogether. ${ }^{7}$

\section{OVERALL DISCUSSION}

Web-based auctions have become one of the great successes of the Internet, a success that has not diminished even after many other Web-based services have lost their initial popularity. The growing importance of online auctions has attracted the attention of consumer researchers who have studied such issues as herding behavior (Djolakia \& Soltysinski, 2001) and the impact of reserve prices (Häubl \& PopkowskiLeszczyc, 2001). Still, our understanding of buyer (bidder) behavior in online auctions is rather limited. In particular, acquiring an item through online auctions is different in important ways from typical purchases of goods and services, and these differences

\footnotetext{
${ }^{7}$ Any such interpretation is naturally dependent on how we conceptualized duration, opponents, and quasi-ownership. Different conceptualizations could potentially lead to different conclusions.
}

can have significant influences on consumer preferences, decision processes, and satisfaction (Ariely \& Simonson, 2003).

Consistent with prior decision research (Staw, 1976), we focused the current investigation on the role of the dynamic aspect of online auctions - the influences of a bidder's behavior (either her own behavior or the behavior of others) at one stage of the auction on behavior at a later stage of the auction. The relevance of this analysis of online auctions is clear. Auctions provide a dynamic environment in which prices are revealed over time and in which the behavior of others is likely to influence the emotional involvement of the bidder with the auction and the item in question. Specifically we present two experiments, both of which provide support for quasi-endowment and opponent effects as mechanisms that could underlie nonnormative behavior in dynamic pricing environments such as online auctions.

Our findings also provide another explanation for the common empirical observation of multiple bids by the same individual. Although multiple bidding is not necessarily contrary to standard economic theory predictions (if we assume, for example, that bidding is pleasurable or costless), it is still likely that multiple bidding and sniping stems from non-rational considerations by at least some of the bidders. ${ }^{8}$

In particular, we show that even if bidders know the precise private value of the item, they may still bid multiple times, since their valuations change due to changes in the auction environment. The central finding here is that bidders might have different subjective valuations for winning the same item in different auction experiences, thus resulting in different maximum bids. Similarly, if the attributes of the auction experience change over time, the subjective valuation can also change, leading to multiple bids. Therefore, conditions that can otherwise be seen as irrelevant might influence bids. These conditions might include the number of people in the auction, how aggressively they act, how long a person has

\footnotetext{
${ }^{8}$ For a wonderful treatment of the conditions under which the irrational behavior of a few bidders could lead to deviation from the optimal second-price bidding strategy, see Roth and Ockenfels (2002).
} 
participated in the auction, and for how long the person has been in the lead. These findings also offer an explanation as to why many people place bids very close to the end of the auction. If individuals are influenced by others' bids, then sophisticated bidders will try to prevent unnecessary price wars by not bidding early.

More generally, the results of the two experiments presented here join a tradition of research on the precedents of value assessments. A great deal of decision research has shown that consumers often have difficulty assessing the values of goods and services, including everyday products such as paper towels and pens (Simonson \& Tversky, 1992). Instead, in many cases, consumers refine and construct their value assessments and preferences when faced with the need to make decisions. (For a recent review, see Bettman, Luce, \& Payne, 1998.) Preference construction has been shown to be sensitive to the framing of options (Levin \& Gaeth, 1988; Tversky \& Kahneman, 1986), characteristics of the decision task (Carmon \& Ariely, 2000; Fischoff, 1982; Nowlis \& Simonson, 1997; Tversky, Sattath, \& Slovic, 1988), and the choice context (Huber, Payne, \& Puto, 1982). Given that preference uncertainty and construction are fundamental characteristics of consumer decision-making, there is no reason to believe that they will not apply to decisions involved in online auctions. Thus, participants in online auctions are likely to be influenced by various value indicators that will impact their preferences and willingness to bid for an auctioned item. In the context of online auctions, some of the unique factors are likely to be ones that are invoked by the dynamic aspect of the auction, such as quasiendowment and competition.

Note that while laboratory experiments have the advantages of precise control and random assignment, they also lack realism, some of the incentives found in the real world, and finally the inclusion of measurements over a long duration to allow examination of behavior under conditions of high expertise-thus limiting the generalizations we can draw from them. While this criticism applies to much laboratory-based research, a particularly exciting aspect of research on online auctions is the fact that field data is readily available to researchers. Although the current work focused on laboratory experimentation, we also examined bidding histories of 115,325 eBay auctions for DVDs held during October 2002 to see if this data points in similar directions.

In particular, we focused on auctions for DVDs in which we knew the final prices that were submitted to the proxy bidding system on eBay (not only the second prices posted to the public). The median number of bidders in these auctions was four with one bidder observed at the 5 th percentile and 10 bidders at the 95 th percentile. These auctions typically lasted a week and on average each individual bidder was in the lead approximately once. The analysis revealed that the final bids (which we assume are their true valuations) are correlated with the number of times the final winners of the auction have been in the lead, and the number of other active bidders. Further analysis, which eliminated the few DVDs that sold at a price of $\$ 100$ or more, shows that for every extra person that participated before a bidder's last bid, that last bid increased by about $\$ 2.50$ during the last day of the auction and by approximately $\$ 1.50$ on previous days. A separate analysis revealed that for every extra time a bidder was in the lead, his bid increased by about $\$ 5$ during the last day and by about $\$ 4$ on previous days.

Of course, we need to use caution when interpreting these results, since this kind of data falls short in terms of our ability to causally relate the behavior to a single theoretical construct due to general endogeneity problems. Among other problems, we cannot guarantee that a bidder's ability to take the lead was random. After all, the bidders that were in the lead more often are more likely to have had higher than average valuations for the item. Moreover, we cannot guarantee that the DVDs were private-value goods (although this category is probably one of the most likely to include private-value items).

Thus, while these data are inconclusive, the observed patterns' resemblance to our lab results increases our confidence that the hypothesized effects are real. Understanding consumer behavior in online auctions most likely requires a joint reliance on laboratorybased experimental evidence, field data, and field experiments. 


\section{Managerial Implications}

The current work attempted to shed some light on the reasons why bidders increase their bids as the auction progresses, in particular toward the end of the auction (Roth \& Ockenfels, 2002). This observed behavior and the associated findings regarding the reasons for it could have significant implications for managers, whether they are buyers, sellers, or third party auction site managers.

Bidders. In many cases, individuals and firms are turning to auction sites in an attempt to get a lower price for material and products. Individual consumers as well as purchasing managers could be afflicted by the quasi-endowment and opponent effect biases and bid more than their core valuation. The notion that no one would bid more for a commodity item than what they could buy it for on the retail market has been shown to be false in the realm of consumer goods. Ariely and Simonson (2003) found that, at least under some circumstances (books, CDs, DVDs), consumers can end up paying higher prices in online auctions than they would buying the same items in standard published price settings. Whether or not professional procurement agents are somehow immune is, at this point, a matter of conjecture. To the extent that they are not, participation in dynamic auctions that take place over time (unlike, for example, sealed-bid secondprice auctions) could be hazardous to their profits.

Sellers and Third-Party Site Managers. There are strategies that a seller can use to increase attachment and competition. For example, attachment can increase if the duration of the auction is longer, if bidders are encouraged to start bidding early, and if bidders are not notified immediately when someone has bid above their price. ${ }^{9}$ Similarly, competition can be increased by managing the quantities that are offered for sale at any point in time, by directing more people to purchase in this channel, by using lower starting prices, and by illegal methods such as bid shilling (bidding on one's own product in order to create the feeling of competition). While the current work seems to suggest that these strategies can increase the rev-

\footnotetext{
${ }^{9}$ Not notifying bidders that they have been outbid could create a situation where multiple bidders simultaneously believe they are the highest bidder.
}

enues of the seller, it is unclear whether they are going to offer a long-term benefit or detriment. For example, it is possible that bidders who will pay higher prices in an auction will realize that they have overpaid, and in the long run will choose not to use auction sites that allow such tactics.

In conclusion, the implications of the current work are twofold. First, to the extent that the increases in bids as the auction progresses represent a bias rather than a change in core valuation, bidders should be aware of these potential biases and take actions to de-bias themselves (Fischoff, 1982). One such method of debiasing, particularly effective in second-price auctions, is to submit their true valuation and not look again until after the auction is complete. However, this strategy has limited usefulness since it is effective only if all bidders commit to it. A second, more strategic approach is to precommit to a maximum price and not go above it even if one submits multiple bids for strategic reasons (such as when bidding against naïve bidders). The final implication is that sellers as well as the providers of the auction marketplace should be aware that the information that is shared or emphasized in the auction could have strategic influences on bidding strategy, prices, and ultimately on the attractiveness of using the auction mechanism.

\section{Research Limitations and Future Research}

The two proposed mechanisms (quasi-endowment and opponent effect) are an attempt to explain a specific phenomenon whereby individuals increase their bids as the auction progresses. The experimental results suggest that these two mechanisms at least partially explain this tendency. Yet the effects of competition and quasi-endowment are general mechanisms that can have much broader implications while also being interesting for their own sake.

With regards to quasi-endowment, one can ask how this virtual ownership is different from real ownership. Is it weaker? Does it have a different time course? Is it as immediate as real ownership? Other questions involve the nature of ownership, attachment and more generally the endowment effect. Is the endowment effect due to the imagination of ownership? Is it related to individuals' ability for attachment? Is it 
linked to the duration of real or imagined ownership? Does the endowment effect strengthen when consumers take actions toward an item, such as buying it or bidding on it? How does this effect change as a function of the type of product?

In terms of competition, it is important to ask the question of why the competition effect exists in the first place. Has evolution left us hardwired to enjoy competition? Do we value objects more due to the perception of scarcity (Cialdini, 2001)? Or perhaps it is a natural tendency to base assessments of value on the opinions of others even in cases where they do not add any real information (for example, with private-value goods such as commodities)? A better understanding of competition might also shed some light on the relative homogeneity in preferences across individuals and more generally on herding behaviors.

\section{REFERENCES}

Ariely, D., Ockenfels, A., \& Roth, A. (2004). An Experimental Analysis of Ending Rules in Internet Auctions (Working Paper). Cambridge, MA: MIT.

Ariely, D., \& Simonson, I. (2003). Buying, Bidding, Playing or Competing?: Value Assessment and Decision Dynamics in Online Auctions. Journal of Consumer Psychology, 13(1-2), 113-123.

Bajari, P., \& Hortacsu, A. (2003). Cyberspace Auctions and Pricing Issues: A Survey of Empirical Findings. In D. Jones (Ed.), New Economy Handbook (Chap. 7, pp. 163-211). San Diego, CA: Academic Press.

Bajari, P., \& Hortacsu, A. (2004, June). Economic Insights From Internet Auctions. Journal of Economic Literature, 42(2), 457-486.

Bar-Hillel, M., \& Neter, E. (1996, January). Why Are People Reluctant To Exchange Lottery Tickets. Journal of Personality and Social Psychology, 70, 17-27.

Beggan, J.K. (1992). On the Social Nature of Nonsocial Perception: The Mere Ownership Effect. Journal of Personality and Social Psychology, 62(2), 229-237.

Beggan, J.K., \& Scott, A. (1997). More There Than Meets Their Eyes: Support of the Mere Ownership Effect. Journal of Consumer Psychology, 5(3), 285-297.

Bem, D.J. (1965). An Experimental Analysis of SelfPersuasion. Journal of Experimental Social Psychology, 1(3), 199-218.

Bettman, J.R., Luce, M.F., \& Payne, J.W. (1998, December). Constructive Consumer Choice Processes. Journal of Consumer Research, 25, 187-217.

Carmon, Z., \& Ariely, D. (2000). Focusing on the Foregone: How Value Can Appear So Different to Buyers and Sellers. Journal of Consumer Research, 27(3), 360-370.
Cialdini, R. (2001). Influence: Science and Practice (4th ed.). Boston: Allyn \& Bacon.

Djolakia, U.M., \& Soltysinski, K. (2001). Coveted or Overlooked?: The Psychology of Bidding for Comparable Listings in Digital Auctions. Marketing Letters, 12(3), 225-237.

Fischoff, B. (1982). Debiasing. In D. Kahneman, P. Slovic, \& A. Tversky (Eds.), Judgment Under Uncertainty: Heuristics and Biases (pp. 442-444). Cambridge: Cambridge University Press.

Häubl, G., \& Popkowski-Leszczyc, P. (2001). The Effects of Minimum Prices on Value Judgments in Auctions (Working Paper). Edmonton: School of Business, University of Alberta.

Häubl, G., \& Popkowski-Leszczyc, P. (2004). Bidding Frenzh: How the Speed of Competitor Reaction Influences Product Valuations in Auctions (Working Paper). Edmonton: School of Business, University of Alberta.

Hossain, T. (2003). Learning by Bidding (Working Paper). Princeton, NJ: Princeton University.

Huber, J., Payne, J.W., \& Puto, C. (1982). Adding Asymmetrically Dominated Alternatives: Violations of Regularity and the Similarity Hypothesis. Journal of Consumer Research, 9, 90-98.

Kahneman, D., Knetsch, J.L., \& Thaler, R.H. (1990), Experimental Tests of the Endowment Effect and the Coase Theorem. Journal of Political Economy, 98(6), 1325-1348.

Kahneman, D., \& Tversky, A. (1979). Prospect Theory: An Analysis of Decision Under Risk. Econometrica, 47(2), 263-291.

Kaplan, A., \& Middleton, J. (2002). Achievement Goals and Goal Structures. In C. Midgley (Ed.), Goals, Goal Structures, and Patterns of Adaptive Learning (pp. 21-53). Mahwah, NJ: Lawrence Erlbaum Associates.

Levin, I.P., \& Gaeth, G.J. (1988). How Consumers Are Affected by the Framing of Attribute Information Before and After Consuming the Product. Journal of Consumer Research, 15, 374-378.

Loewenstein, G. (1996). Out of Control: Visceral Influences on Behavior. Organizational Behavior and Human Performance, 65, 272-292.

Lucking-Reiley, D., \& Reeves, D. (1999). Pennies From eBay: The Determinants of Price in Online Auctions (Working Paper). Nashville, TN: Vanderbilt University.

Nowlis, S.M., \& Simonson, I. (1997, May). Attribute-Task Compatibility as a Determinant of Consumer Preference Reversals. Journal of Marketing Research, $34,205-218$.

Ockenfels, A., \& Roth, A.E. (forthcoming). Late and Multiple Bidding in Second Price Internet Auctions: Theory and Evidence Concerning Different Rules for Ending an Auction. Games and Economic Behavior. 
Pierce, J.L., \& Kostova, T. (2002). The State of Psychological Ownership: Integrating and Extending a Century of Research. Review of General Psychology, 7(1), 84-107.

Rasmusen, E. (2003). Strategic Implications of Uncertainty Over One's Own Private Value in Auctions (Working Paper). Bloomington: Indiana University.

Rosch, E. (1973). Natural Categories. Cognitive Psychology, 4(3), 328-350.

Rosch, E. (1975). Cognitive Representation of Semantic Categories. Journal of Experimental Psychology: General, 104(3), 192-230.

Roth, A.E., \& Ockenfels, A. (2002). Last-Minute Bidding and the Rules for Ending Second-Price Auctions: Evidence From eBay and Amazon Auctions on the Internet. The American Economic Review, 92(4), 1093-2004.

Shafir, E., \& Simonson, I. (2000). Reason-Based Choice. In D. Kahneman \& A. Tversky (Eds.), Choices, Values, and Frames (pp. 597-619). Cambridge: Cambridge University Press.

Simonson, I., \& Tversky, A. (1992, August). Choice in Context: Tradeoff Contrast and Extremeness Aversion. Journal of Marketing Research, 29, 281-295.
Staw, B. (1976). Knee-Deep in Big Muddy: A Study of Escalation of Commitment to a Chosen Course of Action. Organizational Behavior and Human Performance, 16, 172-186.

Strahilevitz, M.A., \& Loewenstein, G. (1998). The Effect of Ownership History on the Valuation of Objects. Journal of Consumer Research, 25, 276-289.

Thaler, R.H. (1980, March). Toward a Positive Theory of Consumer Choice. Journal of Economic Behavior and Organization, 1, 39-60.

Tversky, A., \& Kahneman, D. (1986). Rational Choice and the Framing of Decisions. Journal of Business, 59, 251-278.

Tversky, A., \& Kahneman, D. (1991, November). Loss Aversion in Riskless Choice: A Reference-Dependent Model. Quarterly Journal of Economics, 106, 1039-1062.

Tversky, A., Sattath, S., \& Slovic, P. (1988). Contingent Weighting in Judgment and Choice. Psychological Review, 95, 371-384.

Vickrey, W. (1961). Counterspeculation, Auctions, and Competitive Sealed Tenders. Journal of Finance, 16(1), 8-37. 